\title{
Experimental testing of medium scale GFRP reinforced concrete frames
}

\author{
George Hopartean ${ }^{1, *}$, Ted Donchev ${ }^{1, *}$, Diana Petkova ${ }^{1}$, Costas Georgopoulos ${ }^{1}$, Mukesh Limbachiya ${ }^{1}$ and Noel Parnada $^{1}$ \\ ${ }^{1}$ School of Engineering and the Environment, Faculty of Science, Engineering and Computing, Kingston University, London, UK
}

\begin{abstract}
Fibre reinforced polymers (FRP) have been used as strengthening for existing RC structures for many decades. Lately, there has been a lot of interest in using FRP as internal reinforcement in beams, slabs and columns. One potential area of application could be reinforced concrete frames internally reinforced with GFRP bars. With limited research in this direction, the objective of this publication is to assess the behaviour of glass FRP (GFRP) reinforced concrete frames under reversed cyclic lateral in plane loading and to analyse the seismic performances of such elements. For the purpose of this paper, experimental testing of two $1 / 3$ scaled down frames is conducted in displacement-controlled mode with the loading history according to ACI 374.1-05. The control sample is reinforced with conventional steel reinforcement and the results obtained are compared with the sample reinforced with GFRP bars. In summary, observations on the sample behaviour at specified drift ratio such as load-displacement behaviour, envelope curves and energy dissipation are presented.
\end{abstract}

\section{Introduction}

The use of fiber reinforced polymer (FRP) reinforcement as a viable alternative to steel in reinforced concrete structures has been the main interest for many researchers in the last decades. One of the main characteristics of the FRP bars is attributed to their noncorrodible nature. Consequently, there have been many successful applications reported in the literature in the use of FRP bars as main reinforcement in new reinforced concrete (RC) elements, such as beams, slabs and columns. However, very limited research has been conducted to study the behaviour of frames subjected to seismic loading.

In 2004, Said and Nehdi [1] investigated the performance of steel-free GFRP-reinforced beamcolumn joints. Two full-scale beam column joints, one reinforced with steel and the other with GFRP, were tested under reversed cyclic loading. The results were acceptable in terms of drift demand. Similarly, Mady et. al. [2] in 2011 investigated the seismic behaviour of beam-column joints reinforced with GFRP bars and stirrups. Five full scale column beam joints were tested under seismic loading and the results indicated the feasibility of using GFRP bars and stirrups as internal reinforcement in beam column joints. Moreover, similar studies [3,4] indicate that concrete frames reinforced with GFRP are able to withstand significant lateral displacement. Aliasghar-Mamaghani et al. [5] suggest that frames reinforced with GFRP bars show higher strength than frames reinforced with steel bars under seismic loads. Current publications [6] for GFRP reinforced concrete frames argue that the existing design codes have little or no seismic provisions for these types of structures due to lack of data and research in this area.
This paper presents the experimental results of $1 / 3$ concrete frames reinforced with bent GFRP bars subjected to reversal cyclic loading. It represents a continuation of research conducted at Kingston University as published at FRPRCS 14 [7].

\section{Experimental program}

\subsection{Test specimens}

Two $1 / 3$ scale down reinforced concrete frames were constructed and tested in the department of Civil Engineering at Kingston University, London.

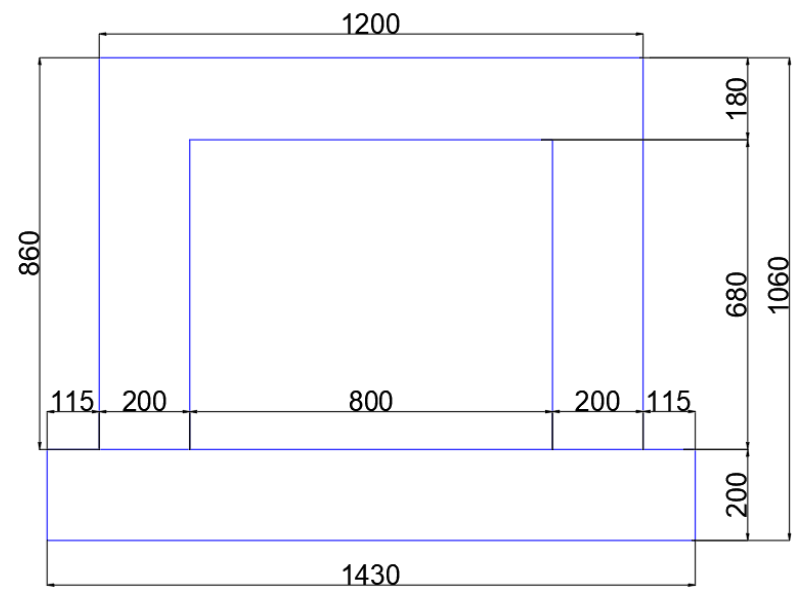

Fig. 1. Overall dimensions of both specimens

The control sample was a frame reinforced with conventional longitudinal steel and steel stirrups (SS) 
while the second frame was reinforced with longitudinal GFRP bars and steel stirrups (GS).

The test specimens were of identical geometry and reinforcement details. Figure 1 shows the overall dimensions of the specimens, which were $1200 \mathrm{~mm}$ by $860 \mathrm{~mm}$. The column heights were $860 \mathrm{~mm}$ with a cross section of $120 \times 200 \mathrm{~mm}$ while the beam length was 1200 $\mathrm{mm}$ with a cross section of $120 \times 180 \mathrm{~mm}$. The foundation beam with a cross section of $200 \times 300 \mathrm{~mm}$ was reinforced with 8 bars of $10 \mathrm{~mm}$ diameter so as to ensure sufficient stiffness is provided to the frame.

Figure 2 shows the reinforcement details of both specimens. The columns were reinforced with 8 rebars of $6 \mathrm{~mm}$ diameter while the beam was reinforced with 4 rebars of $6 \mathrm{~mm}$ in diameter. The stirrups were $4 \mathrm{~mm}$ diameter.

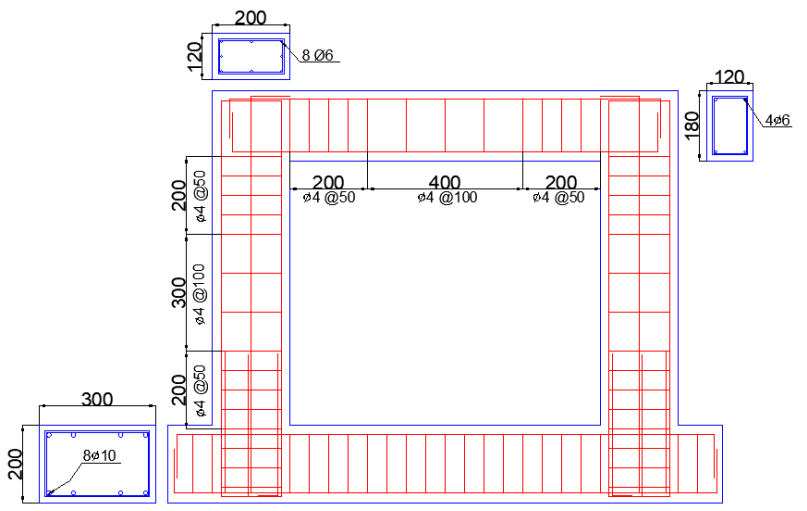

Fig. 2. Reinforcement details of specimens

\subsection{Material properties}

The specimens were constructed in the laboratory by using normal-weight mixed concrete with maximum aggregate size of $10 \mathrm{~mm}$. The frames were cast and wetcured in a horizontal position for 28 days. The targeted 28-day concrete compressive strength was C30/37.

Two types of bent reinforcing bars were used for building the frames: conventional steel and GFRP bars as shown in the Figure 3.

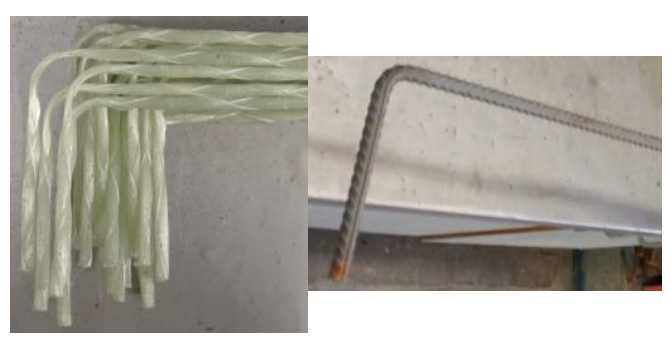

Fig. 3. Bent reinforcement bars

All the bars used in the experiment were anchored by using 90-degree hooks. The mechanical properties of the GFRP bars provided by the manufacturer are listed in Table 1 along with the properties of the steel bars.
Table 1. Mechanical properties of GFRP bars provided by manufacturer

\begin{tabular}{|c|c|c|c|}
\hline $\begin{array}{c}\text { Bar } \\
\text { type }\end{array}$ & $\begin{array}{c}\text { Bar diameter } \\
(\mathrm{mm})\end{array}$ & $\begin{array}{c}\text { Modulus of } \\
\text { elasticity (GPa) }\end{array}$ & $\begin{array}{c}\text { Tensile } \\
\text { strength (MPa) }\end{array}$ \\
\hline $\begin{array}{c}\text { GFRP } \\
\# 6\end{array}$ & $>6$ & $>40$ & $>900$ \\
\hline $\begin{array}{c}\text { Steel } \\
\# 6\end{array}$ & 6 & 200 & 500 \\
\hline
\end{tabular}

\subsection{Test set-up and instrumentation}

The experimental program consisted of testing two frames up to failure under reversed cyclic loading. The specimens were bolted to the strong reaction frame with the anchorage bolts from the RC foundation. The lateral load was applied at the beam level in the in-plane horizontal direction using a screw jack, electric motor and invertor as shown in Fig. 4.

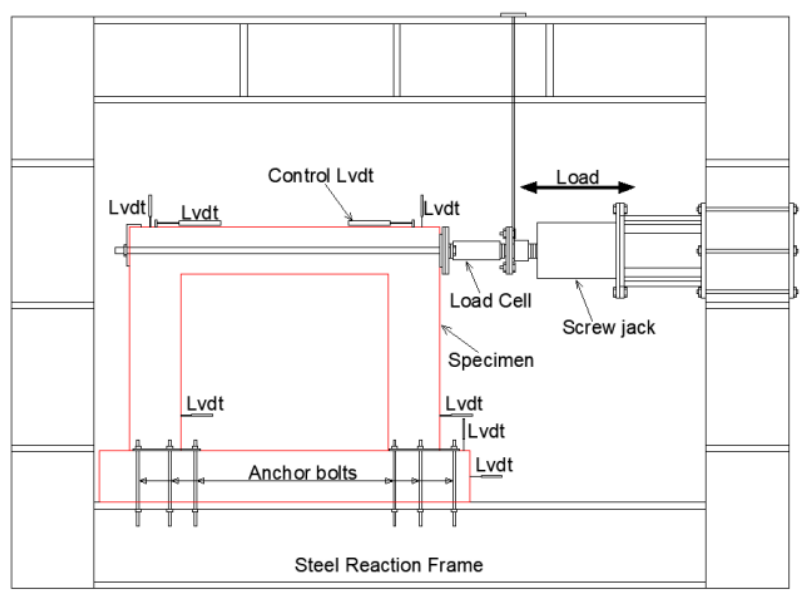

(a) Schematic drawing of set up

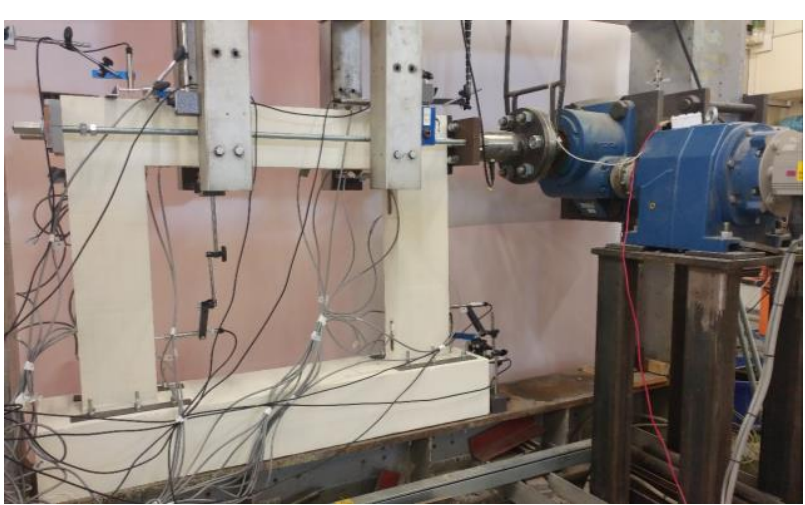

(b) Photo of set up

Fig. 4. Test setup: (a) Schematic drawing of set up; (b) Photo of set up

The pushing and pulling loading mechanism were possible by using high strength studs which were attached along the middle longitudinal axis of the beam and were secured at both ends with thick steel plates.

The load applied to the specimens in both directions was monitored in real time through a $500 \mathrm{kN}$ load cell that was attached to the jack. Six linear variable displacement transducers (LVDTs) were attached to measure the displacement of the frame and two LVDTs to monitor the movement of the foundation (if any). 
Strain gauges were installed on the reinforcing bars and linear wire gauges (PL-60-11 type) on the concrete. The acquisition rate was 10 readings per second.

The loading procedure consisted of one displacement-controlled phase, which was based on ACI-374.1:05 [8] as shown in Figure 5. During this phase, three fully reversed cycles were applied at each drift ratio.

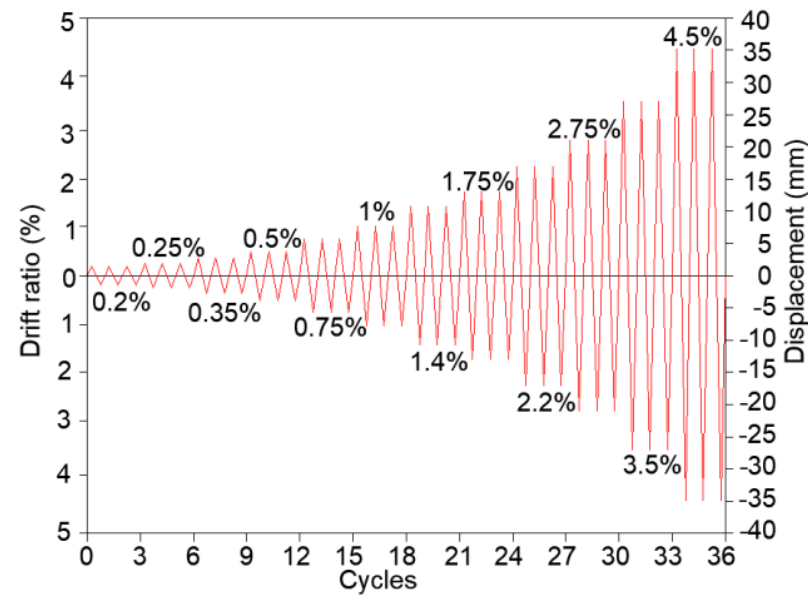

Fig. 5. Loading history

\section{Test results and observations}

Figure 6 illustrates the load-displacement hysteretic curves and photos for both specimens at the last drift.

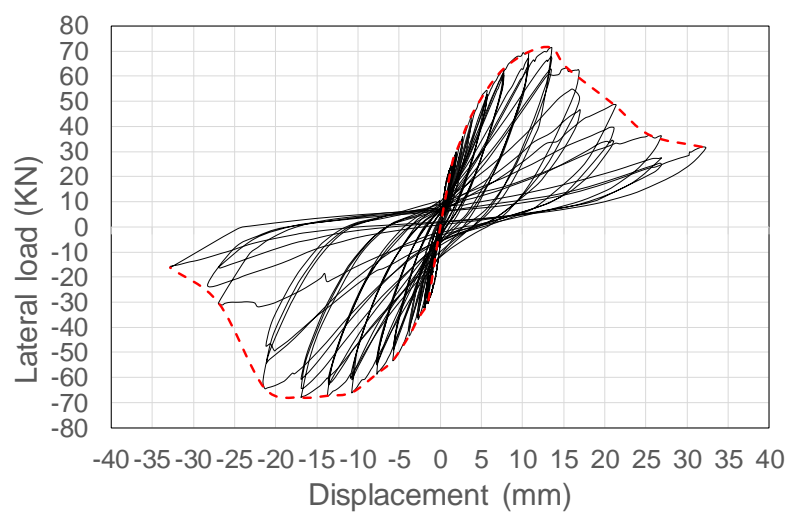

(a) Steel Sample (SS)

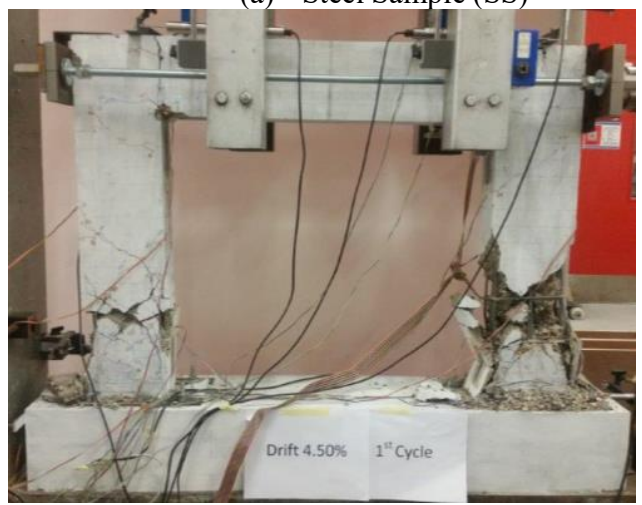

The envelope load-displacement relationship is indicated with a red dashed line on the hysteretic graph. Both specimens, SS and GS, showed almost symmetric responses in pushing and pulling directions as shown in the figure 6. They were both tested up to failure.

At the drift ratio of $1.75 \%$ which is at $13.5 \mathrm{~mm}$ displacement, the SS specimen recorded a peak load of $71 \mathrm{kN}$ in the pushing direction. In the pulling direction it reached its maximum load of $68 \mathrm{kN}$ at a drift ratio of $2.2 \%$ which is at $16.9 \mathrm{~mm}$ displacement. In general, the SS sample exhibited lower resistance in pulling than in pushing and with a difference of $3 \mathrm{kN}$ at maximum load. The maximum displacement the specimen reached was $32 \mathrm{~mm}$ in both directions.

The GS specimen reached the maximum load of 69 $\mathrm{kN}$ and $63 \mathrm{kN}$ respectively in the pushing and pulling directions at the same drift ratio of $3.50 \%$ which is at 26 $\mathrm{mm}$ displacement. The GS sample showed a slightly higher resistance in pulling than in pushing up to a drift ratio of $1.75 \%$. After that point, the resistance changed, becoming higher in pushing than in pulling mode. The difference at maximum load between the directions was only $6 \mathrm{kN}$. The maximum displacement the specimen reached was $40 \mathrm{~mm}$ in both directions.

The crack formation and development was almost symmetrical in pushing and pulling directions for both specimens.

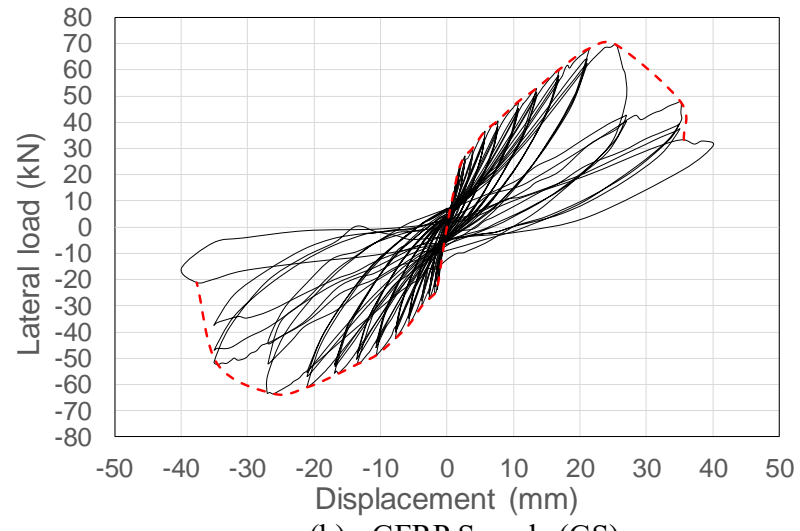

(b) GFRP Sample (GS)

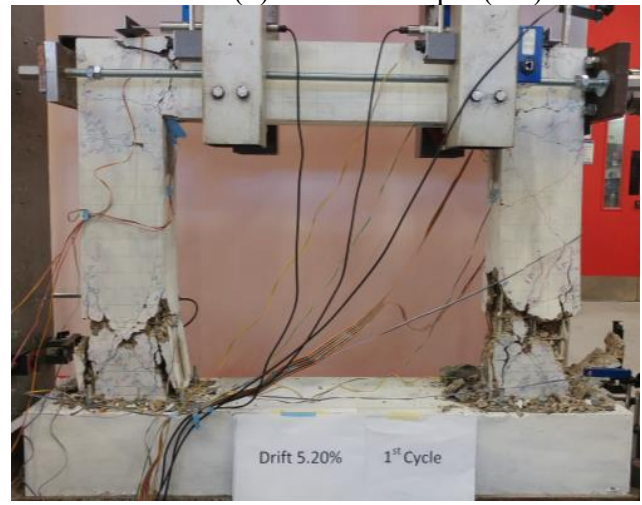

Fig 6 Hysteretic curves and photos of specimens at the last drift: (a) SS sample; (b) GS sample 


\section{Analysis and discussion}

Figure 7 shows the maximum average load from pushing and pulling directions at different amplitudes and it was calculated as the average of the maximum load from both directions from the $1^{\text {st }}$ cycle at each amplitude.

It can be noted that the SS sample is stiffer than the GS sample. Although the SS specimen had a slightly higher load, the GS specimen withstood loading at higher drift ratios.

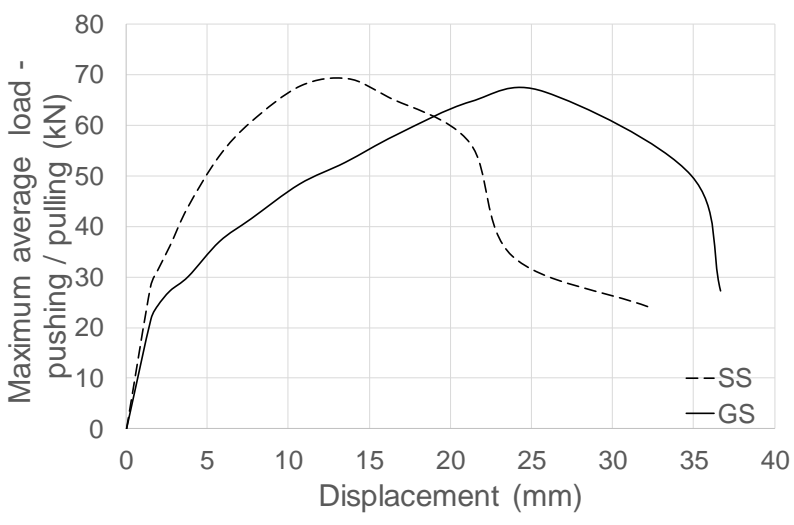

Fig. 7. Maximum average load from pushing and pulling

It can be observed that while the SS specimen reached its maximum load at $1.75 \%$ drift, the GS specimen had the peak at a drift of $3.50 \%$. So, at around $25 \mathrm{~mm}$ in displacement when the GS sample reached its maximum load, the loading capacity of the SS sample had dropped to half of its ultimate load.

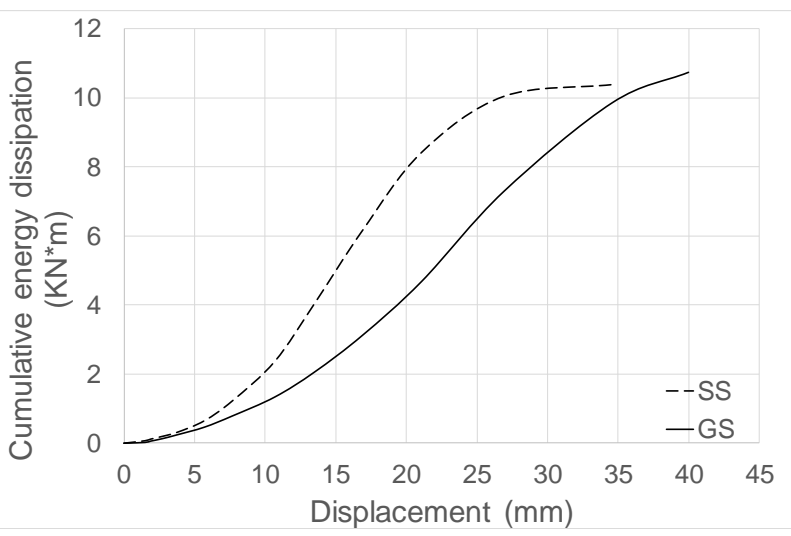

Fig. 8. Cumulative energy dissipation for both samples

Energy dissipation is an important factor in designing structures for earthquake requirements. In seismic areas, moment resisting systems, like RC frames, need to have the ability to dissipate the energy input from ground motion. Lateral load resisting systems with good energy dissipation characteristics are allowing to produce fast decrease of vibrations generated from initial impact.

Figure 8 shows a comparison of the cumulative energy dissipation for the samples. The cumulative energy dissipation was calculated by summation of the enclosed area in the hysteretic loops in successive loaddisplacement cycles. For each cycle, the energy dissipation is calculated as the area that the loop encloses in that particular load displacement graph.

It can be noted that the energy dissipation of the SS specimen is higher than for the GS specimen and up to a drift of $3.5 \%$ it is almost double. After that point, the energy dissipation of the SS sample starts to decrease considerably and at almost $35 \mathrm{~mm}$ displacement, it has almost the same amount of cumulative energy dissipation as the GS sample with a tendency for the GS sample to reach higher values.

\section{Conclusions}

Based on the experimental results, the following conclusions can be drawn:

1. Both tested specimens were able to sustain drift ratios higher than $2.5 \%$.

2. The SS specimen is stiffer than the GS specimen

3. The SS specimen recorded the maximum load of 71 $\mathrm{kN}$ in the pushing direction at a drift ratio of $1.75 \%$.

4. The GS specimen reached the maximum load of 69 $\mathrm{kN}$ in the pushing direction at a drift ratio of $3.50 \%$.

5. The energy dissipation of the SS specimen was higher than that of the GS specimen up to $35 \mathrm{~mm}$ displacement and then decreased above this drift.

The conducted experiments indicate that GFRP reinforced frames are developing approximately same loading capacity as the control frame but the ultimate values of load turned up to be at higher displacement. Therefore, at the displacement of $25 \mathrm{~mm}$, when the GS sample reached its ultimate load, the load bearing capacity of the SS sample is already reduced to approximately $50 \%$ of its ultimate capacity. During an earthquake event, the behaviour of a GFRP reinforced frame could allow bigger displacements than the conventional RC frames before reaching ultimate load values, this way allowing for better distribution of stresses.

The authors would like to express their gratitude for the GFRP bent bars provided by ATP construction composites, Italy.

\section{References}

1. A.M. Said, M.L. Nehdi, Use of FRP for RC frames in seismic zones: Part II. Performance of steel-free GFRP-reinforced beam-column joints. In: Applied Composite Materials (2004), pp. 227-245

2. M. Mady, A. El-Ragaby, E. El-Salakawy, Seismic behavior of beam-column joints reinforced with GFRP bars and stirrups. In: Journal of Composites for Construction 15(6) (2011), pp. 875-886

3. M. Kazem Sharbatdar, M. Saatcioglu, B. Benmokrane, Seismic flexural behavior of concrete connections reinforced with CFRP bars and grids. In: Composite Structures (2011) 
4. S.K. Ghomi, E. El-Salakawy, Seismic Behavior of Exterior GFRP-RC Beam-Column Connections: Analytical Study. In: Journal of Composites for Construction 22(4) (2018), pp. 04018022

5. M. Aliasghar-Mamaghani, A. Khaloo, Seismic behavior of concrete moment frame reinforced with GFRP bars. In: Composites Part B: Engineering, (2019), pp. 324-338

6. M. Hasaballa, E. El-Salakawy, Anchorage Performance of GFRP Headed and Bent Bars in Beam-Column Joints Subjected to Seismic Loading. In: Journal of Composites for Construction 22(6) (2018), pp. 1-14 04018060

7. G. Hopartean, T. Donchev, D. Petkova, C. Georgopoulos, M. Limbachiya, Z. El Kashik, Experimental investigation of FRP reinforced $R C$ frames under Cyclic in-plane loading, Proceedings of the International Conference FRPRCS14, Belfast (2019)

8. ACI-374.1:05, Acceptance Criteria for Moment Frames Based on Structural Testing and Commentary. In: American Concrete Institute 05 (Reapproved) (2014) 